\title{
Apuntes iniciales para la construcción de una Ecología Política Feminista de y desde Latinoamérica
}

\author{
Evelyn Arriagada Oyarzún \\ Universidad Diego Portales, Santiago, Chile. \\ Email: evelyn.arriagada@udp.cl \\ Antonia Zambra Álvarez \\ Universidad Católica Cardenal Raúl Silva Henríquez, Santiago, Chile. \\ Email:antonia.zambra@ucsh.cl
}

\begin{abstract}
Resumen: La Ecología Política se ha convertido en uno de los enfoques más relevantes para el abordaje de las relaciones ecológico-distributivas en Latinoamérica, generando una corriente intelectual y política con fuerza propia. Sin embargo, sus debates conceptuales han tendido a centrarse en el eje de clase, con un desarrollo menor en otros ejes, como el género. Considerando que las disputas ambientales han demostrado efectos y respuestas diferenciadas entre hombres y mujeres,el presente artículo plantea la necesidad de una Ecología Política Feminista(EPF) al interior de la Ecología Política Latinoamericana. Para ello, se revisan los orígenes y trayectoria de la EPF en el Norte y de los ecofeminismos del Sur y se presenta una revisión situada de trabajos recientes en ambos hemisferios. Con ello, se busca esbozar algunos ejes de articulación, donde los aportes de nuestra región construyan un diálogo crítico y proyecten caminos para la EFP global.

Palabras clave:Género; medioambiente, impactos ambientales diferenciados, feminismo ambiental, movimientos de mujeres.
\end{abstract}

\section{Initial Notes for the Construction of a Feminist Political Ecology of and from Latin America}

\begin{abstract}
Political Ecology has become one of the most relevant approaches to ecological-distributive relations in Latin America, generating an intellectual and political current with its own strength. However, its conceptual debates have tended to focus on the class axis, with less development in other axes, such as gender. Considering that environmental disputes have demonstrated differentiated effects and responses between men and women, this article raises the need for a Feminist Political Ecology (EPF) within Latin American Political Ecology. To this end, the origins and trajectory of the EPF in the North and of the ecofeminisms in the South are reviewed and a review of recent work in both hemispheres is presented. In doing so, it seeks to outline some axes of articulation, where the contributions of our region build a critical dialogue and project paths for global EFP.
\end{abstract}

Keywords: Gender;environment; uneven environmental impacts; environmental feminism; women’s movements.

\section{Notas preliminares para a construção de uma Ecologia Política Feminista de e desde a América Latina}

Resumo: A Ecologia Política tornou-se uma das abordagens mais relevantes para analisar as relações ecológicodistributivas na América Latina, com seu próprio desenvolvimento intelectual e político. No entanto, seus debates conceituais se concentraram no eixo da classe, com menos reflexões em outras dimensões, como o gênero. Considerando que as disputas ambientais têm mostrado diferentes efeitos e respostas entre homens e mulheres, este artigo propõe a necessidade de uma Ecologia Feminista Política (EPF) dentro da Ecologia Política Latino-Americana. Para isso, as origens e a trajetória do EPF - no Norte - e o ecofeminismo do Sul são revisados. Posteriormente, apresentamos uma revisão situada de pesqui- 
sas e experiências recentes em ambos os hemisférios. Com isso, buscamos traçar possibilidades de articulação que levem em conta as contribuições de nossa região, construam um diálogo crítico e projetem caminhos para o EPF global.

Palavras chave: Gênero;meio ambiente, impactos ambientais diferenciados, feminismo ambiental, movimento de mulheres.

\section{Introducción: hacia enfoque feminista en la ecología política latinoamericana}

La incorporación del pensamiento posthumanista ${ }^{1}$ y la teoría poscolonial/decolonial en Ecología Política ha posibilitado una apertura epistemológica de este campo de estudio y práctica política más allá de la tradición intelectual en economía política.Esto a permitido la reinterpretaciónde aquellarelación intrínseca entre naturaleza-sociedadque alguna vez introdujesenlas corrientes iniciales del ecofeminismo(Vandana Shiva, María Mies, Carolyne Merchant) para imaginar múltiples formas de ensamblaje socio-ecológico (Elmhirst, 2018; Ojeda, 2011). Esta misma apertura ha permitidosentar los cimientos de unaEcología Política Latinoamericana,así como tambiénha evidenciado la necesidad de repensar formas de abordaje teóricoprácticapara un renovado proyecto de Ecología Política Feminista, tanto en el mundo como en América Latina.

En Ecología Política,esta apertura teórico-práctica ha significadorebasar la comprensión de naturaleza sujeta al dominio de la ciencia y/o los modos de producción económico, para sostener que la idea de "naturaleza” se constituye como un objeto de disputa y apropiación a ser transformada, resignificada desde diversas corrientes interpretativas (Leff, 2006). En esta misma línea, el desarrollo de una Ecología Política Latinoamericana (en adelante EPL) se nutrede las contribuciones de Joan Martínez-Alier ${ }^{2}$ en torno a la existencia de (otros) procesos de significación, valoración y apropiación de la naturaleza más allá de su apreciación económica y la asignación de normas ecológicas a la economía (Leff, 2006), paraahondarsobre la historia de colonialización y relaciones de poder que han marcadola particularidad del territorio latinoamericano en un contexto planetario cada vez más globalizado. Así, autores como Enrique Leff (2006), Arturo Escobar (2011) o Héctor Alimonda (2006, 2011), dan cuenta de la marca invisible que los beneficios aparejados por la modernidad han dejado en nuestro continente, el cual ha sido - al mismo tiempo - receptáculo de cargas ambientales y fuente de recursos de una economía extractivista, herencia de una historia ambiental de colonización.

Para Héctor Alimonda (2011), pensar en esteproyecto de Ecología Política en América Latina comprende considerar el amplio espectro de relaciones de poder vigentes en el continente desde el período colonial hasta el presente, incluyendo el papel del Estado y sus políticas en su relación con el medioambiente. Tomar en cuenta esta matriz de relaciones de poder, que tiene como argumento central el acceso a la tierra y control sobre los recursos naturales desde el periodo de la Colonia, nos obligaría, a rescribir la historia ambiental de América Latina desde una mirada decolonial (Alimonda, 2011), es decir,romper con el origen colonial de la historia ecológica para redescubrir la particularidad y heterogeneidad de los paisajes latinoamericanos y reorganizar la naturaleza impuesta por una economía global de mercado (Alimonda 2006).

$\mathrm{Al}$ analizar la trayectoria reflexiva que ha ido tomando la EPL, sin embargo, se evidencia que las preocupaciones en torno al género, así como la incorporación de la teoría feminista para el abordaje de las relaciones de poder en el continente, no han sido lo suficientemente consideradas dentro del proyecto en su conjunto. Según lo señalado por Laura Pérez Prieto (2017), la Ecología Política, tan centrada aún en los conflictos ecológicodistributivos de lógica Norte-Sur, ha olvidado problematizar en esta articulación de heterogeneidades situadas, las distintas formas de violencia que emergen no solo desde la diferencia de clase o etnia, sino también desde el género. En este sentido, un acercamiento tanto a la epistemología feminista, como a los ecofeminismos del Sur, nos permitiría visibilizar e incorporar mayor multiplicidad de voces con el fin de empujar, desde varios frentes, un proyecto intelectual de EPL. Un proyecto, según Prieto (2017), que se feminizara, se descolonializara y se democratizara, al mismo tiempo, mediante la creación de alianzasnecesarias para apoyar procesos transformadores para todas y todos en su relación con la naturaleza. 
La necesidad de una mirada feminista en la EPL se hace aún más urgente atendiendo al contexto actual en la región, cuya trayectoria ha mostrado una creciente feminización de las luchas, particularmente las de tipo ambiental (Svampa, 2015). El brote de mujeres activistas ambientales asesinadas (Berta Cáceres, Marielle Franco, Macarena Valdés) así como de dirigencias femeninas que buscan enfrentar y/o dar solución ala crisis socioambiental las Mujeres de zona de sacrificio Quintero-Puchuncaví en Resistencia (Chile), la Cooperativa de mujeres productoras de café que siguen el sistema tradicional de agrosilvicultura Lenca (Honduras) o el rol de las mujeres en CLOC-La Vía Campesina (que agrupa a mujeres de toda América Latina), nos interpelan de manera transversal, para obligarnos a rearticular posiciones dentro de la matriz de relaciones de poder a diferentes escalas.

Desde esta perspectiva, la tradición intelectual en Ecología Política Feminista (en adelante EPF) ha venido adoptandouna postura crítica hacia la apertura de nuevas temáticas de debate sobre la relación géneromedioambiente, tales como la construcción social de género mediadas en y a través de materialidades ecológicas, la visibilización de(otras) formas de conocimiento desde una mirada decolonial o bien la profundización de la idea de interseccionalidad. En todos estos casos, se busca acortar la brecha teoría-práctica que ha resonado en los desarrollos recientes de la EPF (Hawkins y Ojeda, 2011), de marcada producción intelectual anglosajona, evidenciando la necesaria revisión teórico-conceptual y metodológica con la que se han planteado elementos constitutivos de la EPF tales como interseccionalidad, relación agencia/estructura o multiescalaridad.

Consideramos, en base a este planteamiento,que la trayectoria histórica del ecofeminismo se presenta aquí como una oportunidad de contribución y diálogo crítico con las EPF del Norte, en tanto la primera se constituye desde una marcada raigambre práctica. Desde las experiencias de ambientalización y feminización de las luchas sociales,los ecofeminismos del surevidencian nuevos horizontes de debate que permiten no solo dar un nuevo impulso a la EPF global sino también pensar en una EPF de y desde América Latina. Para ello también buscamos relevar los aportes de pensadores clásicos de la teoría social latinoamericana tales como Orlando Fals-Borda o Paulo Freire, así como diversas experiencias de diálogo e intercambio de prácticas y saberes (metodologías participativas, investigación-acción), ejemplos que dejan entrever que América Latina dispone de un campo fecundo para la construcción de una Ecología Política Latinoamericana que incorpore una mirada feminista al proceso de construcción y producción de conocimiento social y ecológico.

Partiendo de esta necesidad de problematización, nos situamos en este artículo como académicas e investigadoras, chilenas, latinoamericanas, pero a su vez herederas de un proceso de formación híbrida, con un fuerte componente educativo de pensamiento occidental. Creemosque la tarea de reconocernos desde otra vereda de producción de conocimiento es un desafío que nos acompañará a lo largo de nuestras vidas, y queimplica una tarea constante de observar nuestras propias formas de extractivismo epistémico, así como nuestros prejuicios en el ejercicio de reconocer aquellos espacios que consideramos legítimos en el intercambio de saberes y prácticas socioambientales. En este sentido, lejos de pretender exhaustividad con relaciónlos aportes de la EPF alcampo de la Ecología Política Latinoamericana(puesto que consideramos que ambas estánen permanente construcción), lo que buscamos es efectuar una revisión situada - parafraseando a Elmhirst (2018) - de aquello que resuena en nuestras reflexiones y prácticas recientes. En otras palabras, la presentación de una perspectiva parcial alrededor de un proyecto de Ecología Política Feminista Latinoamericana que, siguiendo sus líneas clásicas de tradición intelectual, profundice y redefina, a su vez que provea de nuevos enfoques y formas de exploración en la compleja relación género- medioambiente.

\section{Ecología Política Feminista (¿del Norte?) versus Ecofeminismo (¿del Sur?)}

La relación entre la Ecología Política Feminista y los ecofeminismos ha estado marcada por distintos acercamientos y distanciamientos. Para comprender estos matices, describiremos brevemente los orígenes y planteamientos de ambas perspectivas, para mostrar sus fortalezas y puntos críticos, pero especialmente para proyectar posibilidades de colaboración y complementación que permitan construir una Ecología Política Feminista desde Latinoamérica. 


\section{Orígenes y fundamentos de la Ecología Política Feminista}

Desde sus orígenes la Ecología Política Feminista mostró la relación porosa y de mutua influencia entre la dimensión académica y la dimensión práctica. De este modo, sus antecedentes remotos nos llevan a los años 70, cuando académicas y activistas llevan muchos de los objetivos y planteamientos de la teoría feminista a los estudios del desarrollo, que surgen frente a programas de planificación e intervención dirigidos hacia los países del Sur. Desde entonces, la EPF se ha nutrido de diversas corrientes, conceptos y teorías tanto del propio feminismo, como de las ciencias sociales y humanidades, para abordar la relación género-medioambiente. Además de las críticas feministas al desarrollo, son particularmente relevantes los planteamientos del ecofeminismo y los estudios feministas de la ciencia (Sundberg, 2017).

En términos académicos, existe relativo consenso en señalar el texto “Ecología Política Feminista” (1996), editado por Diane Rocheleau, Barbara Thomas-Slayter y Esther Wangary, como la obra que cimenta los principales planteamientos de este nuevo subcampo de la Ecología Política (Harcourt y Nelson, 2015; Elmirst, 2011; Sundberg, 2017). En dicho texto, las autoras afirman que existen diferencias en las experiencias, responsabilidades e intereses de hombres y mujeres, en relación con la naturaleza, que no derivan de la biología, sino más bien de las construcciones sociales (y las interpretaciones biológicas) en torno al género. Señalan, además, que estos constructos e interpretaciones varían, de acuerdo con elementos culturalesy espaciales, así como de clase y raza, siendo además susceptibles de ser transformados por mecanismos individuales y sociales (Rocheleau, et al. 2004). El texto plantea avances conceptuales y casos empíricos en torno a tres grandes ejes:1) el conocimiento dependiente del género; 2) los derechos y responsabilidades ambientales dependientes del género y; 3 ) la política ambiental y el activismo de base estructurados con base en el género. Desde la publicación de este libro, queda establecido que las principales ventajas de la EPF, frente a otras perspectivas, serán su énfasis tanto en los elementos estructurales como agenciales de la relación género/ambiente, un acercamiento al género desde la interseccionalidad de las desigualdades, y un abordaje multi-escalar, que conecta simultáneamente las cadenas globales de la economía con las experiencias ocurridas enlo doméstico y local.

Tras la publicación de este texto, la EPF floreció como sub-campo. A través de sus distintas exponentes, se fue construyendo un cuerpo conceptual cada vez más sofisticado, a la vez que revolucionó y promovió importantes debates epistemológicos e innovaciones metodológicas, tanto en la Ecología Política como en los estudios feministas (Sundberg, 2017). De este modo, la trayectoria de la EPF desde los 90 ha sido diversa, oscilante y en constante proceso de revisión.Sin embargo - yaun cuando muchas de sus investigaciones se han llevado a cabo en el Sur global - la mayoría de sus contribuciones se han circunscrito a la mirada de investigadorasdelNorte, principalmente blancas y de clase media. Esto se tradujo por algún tiempo en el predominio de visiones feministas occidentales, con consecuencias diversas en torno a la producción de conocimiento. Así, por ejemplo, la influencia del feminismo occidental implicó privilegiar la observación de ciertas actividades y espacios, mientras otros fueron oscurecidos. Al respecto Sundberg cita el trabajo de Maria Elisa Christie,releva el espacio de la cocina en las construcciones culturales y discursivas de mujeres mexicanas. Esta visión se contrapone a la mirada occidental del feminismo, que vio siempre ese espacio doméstico como el lugar de opresión de las mujeres (Sundberg, 2017).

Tal vez una de las consecuencias más evidentes de esta imposición, fue el rechazo del ecofeminismo (Elmirst, 2018), que por mucho tiempo fue excluido del debate, siendo etiquetado de esencialista. Sin embargo, como veremos a continuación, este rechazo implicó cerrar la posibilidad de reconocer los saberes, realidades y prácticas de las mujeres en los países del Sur, desde las visiones de sus propias protagonistas. Esto, no obstante, podría estar cambiando el escenario actual, debido a la relevancia en el giro decolonial que ha tomado la EPF.

\section{Los ecofeminismos latinoamericanos}

El término ecofeminismo refiere los planteamientos que surgen al alero de diversos movimientos feministas y pacifistas entre los años 70 y 80, en distintos lugares del mundo(Carcaño, 2008). Los aportes más influyentes en aquella época, venían principalmente de Estados Unidos (Ibid.)donde se levanta una crítica a la ciencia, la técnica y al patriarcado, buscando recuperar y resignificar la relación Mujer/Naturaleza y oponiendo la ética del cuidado femenina a la agresividad masculina que habría derivado en guerras y deterioro ambiental 
(Puleo, 2002).Se planteaba que las mujeres se caracterizarían por aptitudes maternales que las harían más propensas al pacifismo y la conservación de la Naturaleza.

Si bien estos primeros esbozos se trazaron en el Norte, los desarrollos posteriores invirtieron la lógica de producción de conocimientos a nivel global. A mediados de los años ochenta, la obra "Stayingalive" de Vandana Shiva, abre la posibilidad de creación de un ecofeminismo poscolonial, que servirá de fuente de inspiración, discusión y reformulación hasta nuestros días. Latinoamérica también tuvo una trayectoria ecofeminista temprana, aunque con menor difusión y posibilidad de influencia en la teoría feminista global (LaDanta LasCanta, 2017). Para las ecofeministas latinoamericanas, esta invisibilización no es casual, y se explica, entre otras cosas, por "la gobernabilidad epistémica del Norte global, con su copiosa movilización de recursos financieros, incluso en las corrientes del pensamiento crítico” (LaDanta LasCanta, 2017, p. 27).

Así, las primeras etapas del ecofeminismo latinoamericano datan de principios de los años 90, como una de las huellas de la Teología de la Liberación (Puleo, 2002). Como el grupo LaDanta LasCanta (2017), durante la Cumbre de la Tierra (en Río de Janeiro) y en el contexto de la emergencia de movimientos indígenas, un grupo de teólogas feministas propuso una cosmovisión propia y pensada desde esta región. Estas religiosas, con vasta experiencia en el trabajo eclesial de base, evidenciaron el sesgo androcéntrico y antropocéntrico de la Teología de la Liberación, incluyendo además reflexiones y acciones en torno al cuerpo de las mujeres(Ibid.).

Este ecofeminismo comparte con sus pares en otras latitudes la comprensión de la equivalencia entre la opresiónde las mujeres y la explotación de la naturaleza, pero tiene particularidades a partir de su interés en las mujeres pobres y defensa de los pueblos indígenas - principales víctimas de la destrucción de la Naturaleza además de la crítica a la discriminación de la mujer en las estructuras eclesiásticas (Puleo, 2002). Si bien tiene exponentes en toda la región, es la brasileña Yvone Gebara su principal referente y el colectivo Con-spirando quien mejor representa su praxis ${ }^{3}$.

Junto a la teología ecofeminista, el espacio latinoamericano también ha visto florecer una serie movimientos de mujeres, cuya inspiración explícita o no, remite a los planteamientos y prácticas del ecofeminismo. Al respecto,Maristella Svampa (2015)plantea la deriva ecofeminista en América Latina, como un fenómeno que no ha ocurrido "por elección, sino por obligación”. Para esta autora, nuestra región (y los países del Sur global) han mostrado una creciente "feminización de las luchas sociales", es decir, un mayor protagonismo de las mujeres de clases medias y populares en los procesos organizativos de base y en las acciones colectivas. Paralelamente, también la región viene experimentando una “ambientalización de las luchas”. En ambos casos, quienes protagonizan estos sucesos rehúyen de ser etiquetados como ecologistas o feministas. Así, para esta autora, lo que se evidencia aquí es más bien un “ecofeminismo de la supervivencia”,similar a los ecologismos populares del Sur, cuyo fundamento es más bien experiencial, y que por tanto surge de la vivencia de mujeres que se han involucrado en procesos de defensa de la salud y la vidaen sus territorios.

El colectivo LaDanta LasCanta (2017) se ha propuesto visibilizar la presencia de estas muchas expresiones colectivas, identificando la existencia de cincuenta organizaciones que se han definido abiertamente como ecofeministas o que se sustentan en lo que ellos llaman un "imaginario ecofeminista”(Finzar, 2017. Citado en LaDanta LasCanta, 2017).Son organizaciones que están presentes en una amplia variedad de países latinoamericanos, desde los años ochenta hasta la actualidad, aunque reconocen la existencia de organizaciones con características similares mucho antes de que se acuñase el término ecofeminismo. Como explican desde aquel colectivo, estas entidades han compartido distintasreivindicaciones sobre derecho y autonomía territorial, soberanía alimentaria, derechos de las mujeres,en toda su diversidad étnica, cultural y/ de clase. Además, sus luchas han incluido la defensa de derechos sexuales y reproductivos, el autocuidado y el autoconocimiento, distintas visiones espirituales y la formación política de mujeres. Recientemente, y en el contexto de la expansión extractivista, han sumado preocupaciones en torno a "la despatriarcalización, la descolonización, la defensa de los derechos colectivos y la protección de las defensoras y losdefensoresdela naturaleza-madrey la TierraPachamama” (LaDanta LasCanta2017, p 41).

Así, es posible apreciar que, más allá de la cosmovisión propuesta por las teólogas ecofeministas, las mayores fortalezas del ecofeminismo latinoamericano residen en su crítica al colonialismo epistémico, en su 
conocimiento de las realidades cotidianas y en su capacidad performativa y política. A partir de ello ha servido como fuente de inspiración y experimentación colectiva, acompañando o promoviendo el quehacer de distintos movimientos y organizaciones de mujeres, indígenas y afrodescendientes, campesinas y/o pobres urbanas en la región. Al mismo tiempo, sus experiencias han nutrido las discusiones y han contribuido a documentar el repertorio de luchas que se sitúan en el corazón de la Ecología Política Latinoamericana. Pero su fuerza práctica y política no ha estado acompañada de una consolidación equivalente en el plano teórico o analítico, y por lo mismo ha sido blanco fácil de críticas, incluso desde otras manifestaciones feministas y ecologistas.

\section{Críticas y posibilidades de apertura en la Ecología Política Feminista}

Para nosotras, la raigambre práctica de los ecofeminismos latinoamericanos se presenta como una oportunidad de contribución y diálogo crítico con las EPF del Norte, tanto para acortar la brecha teoría-práctica presente en los desarrollos recientes de la EPF (Hawkinsy Ojeda, 2011), como para alimentar su continua y necesaria revisión epistemológica, teórico-conceptual y metodológica.Como plantea Kiran Asher:

"No es suficiente leer y teorizar, pero ciertamente es absolutamente necesario porque los 'viejos' tipos de formulaciones y análisis de 'género’ y 'el ambiente’ se están reconstituyendo, sostengo, y las 'viejas' - eso es, eurocéntricas, esencialistas, imperialistas, patriarcales, capitalistas o de cualquier otra forma explotadora - relaciones se están replicando y reforzando en nombre de necesidades 'nuevas' y / o ‘urgentes’ para las intervenciones y soluciones pragmáticas” (Hawkins y Ojeda, 2011, p. 248). ${ }^{4}$

Respecto a estas posibilidades, es importante rescatar que muchas exponentes actuales en la EPF del Norte han hecho un reconocimiento de su posición de privilegio, y han mostrado su apertura frente a las críticas planteadas por activistas e intelectuales del Sur, abriendo nuevas posibilidades para la producción de conocimientos(Elmhirst,2018; Harris, 2015b).Al respecto Harcourt y Nelson (2015) han mostrado la importancia de cuestionar los efectos de estos privilegios, que se traducen en la autoridad legítima para contar historias - que muchas veces se toman "prestadas" de sus protagonistas - o para imaginar mundos posibles, aun cuando estos se consideren "justos" o "verdes". De este modo, la práctica de la EPF, particularmente influenciada por el giro decolonial, implicaría desafiar los propios puntos de vista de sus exponentes, buscar posibilidades para construir conexiones y compartir visiones, además de visualizar futuros alternativos cony entre comunidades más amplias.

A nuestro entender, además del giro decolonial (que profundizaremos en la siguiente sección) la apertura en la EPF del Norte se explica también por el peso de la matriz feminista en este sub-campo, que implica un ejercicio reflexivo de carácter permanente. Lejos de asumir el feminismo simplemente como una corriente de pensamiento o un marco teórico, la adscripción feminista implica una praxis investigativa, donde es vital situarse y transparentar la posición que se toma y el lugar desde el que se habla. En tal sentido, también es fundamental preguntarse en qué medida lo que se escribe, se piensa y se practica contribuye a reproducir o transformar las condiciones de desigualdad que enfrentan los grupos sociales con los que se trabaja y/o investiga. Así, consideramos que la matriz feminista común en las Ecologías Políticas Feministas (del Norte) y los ecofeminismos (del Sur), así como el giro decolonial, abren posibilidades de encuentro entre ambas posturas, permitiendo no solo dar un nuevo impulso a la EPF global sino también pensar en una EPF desde AL.

Desde nuestra visión, además esta praxis situada, reflexiva y en revisión permanente no solo debe servir para mirar críticamente la construcción de conocimientos en la EPF en el Norte, sino que debe constituir una actitud epistemológica que permee también la forma en que construimos conocimiento en el Sur, donde muchas veces replicamos la división jerárquica entre conocimiento académico y no académico, y podemos reproducir o agudizar las desigualdades preexistentes. Adicionalmente, nos interesa extender esta visión reflexiva de la praxis feminista a las relaciones intelectuales y organizaciones, y entre organizaciones y movimientos, pues a veces ellos - tal como nosotros en la academia - tendemos a asumir nuestras interpretaciones como universales y cerramos las puertas a comprender otras formas de pensar y ejercer el activismo ambiental, especialmente cuando no cuestionan abiertamente las formas patriarcales y capitalistas de dominación. 


\section{Nuevos enfoques en la Ecología Política Feminista: contribuciones desde Latinoamérica}

Tras años de vaivenes, revisiones y avances en las investigaciones que se enmarcan en el cruce géneromedioambiente, hoy asistimos a una etapa donde la EPFse ha consolidado como sub-campo de la EP. En esta etapa, se siguen sus líneas clásicas de desarrollo, pero se profundizan y se redefinen, a la vez que se abren nuevos enfoques y formas de exploración. La idea de una mutua relación género-medioambiente, la multiescalaridad de sus abordajes, así como la noción de interseccionalidad, siguen siendo elementos centrales de la EPF, pero asumen nuevos énfasis, especialmente a partir de la influencia transversal del pensamiento postestructuralista, y de las ideas postcoloniales y decoloniales. Sin pretensiones de exhaustividad, en las siguientes líneas mapearemos algunos elementos que nos parecen relevantes en estas discusiones actuales, particularmente agrupados en torno a cuatro temáticas, a saber: a) los aportes estructuralistas y decoloniales; b) los impactos y experiencias generizadas; c) las viejas y nuevas formas de agencia y; d) la EPF como lugar de praxis política. Para cada una de estas temáticas señalaremos contribuciones teóricas, conceptuales, epistemológicas, metodológicas o prácticas, generadas en América Latina, las cuales permiten explorar algunos caminos posibles para quienes se aventuren a construir una EPF desde esta parte del globo.

\section{El terremoto postestructuralista y el giro decolonial en la EPF}

Parte importante de las nuevas orientaciones en la EPF provienen de la influencia del pensamiento postestructuralista en torno al poder, la subjetividad y la agencia de las mujeres (Elmhirst, 2011). Tomando particularmente la obra de Judith Butler (1999), intelectuales como Juanita Sundberg, Leila Harris y Andrea Nigthingale, levantan una visión anti-esencialista del campo de la Ecología Política. Tal como indica Sundberg (2017),ellas retoman la idea de que los cuerpos generizados no tienen una fuente biológica o natural (en el sexo) sino que se constituyen en y a través de prácticas de género, que son reiteradas o performadas cotidianamente. Para el caso de las relaciones ecológicas, esto implica pensar que los cambios e impactos ambientales no solo afectan diferente a hombres y mujeres, sino que también condicionan o re-definen el género mismo(además de otras categorías de diferenciación como la clase o la etnia) (Harris, 2017).Así, no existen relaciones predefinidas entre hombres o mujeres y el ambiente en el que viven, pues estas se construyen mediante prácticas concretas y cotidianas, que se caracterizan por ser espacialmente contingentes y estar cargadas de poder (Sundberg, 2017).

En sus manifestaciones recientes, la EPF también se ha abierto camino de la mano de las teorías decoloniales, pero también aprendiendo de la praxis de diversos movimientos indígenas y campesinos alrededor del mundo. De las teorías decoloniales no solo se crítica la anulación eurocéntrica de cosmologías indígenas(Leff, 2012),sino que se toman estas propias formas de conocimiento - antes excluidas - para robustecer las fuentes de pensamiento, praxis y proyección política de la EPF. Al respecto, un intento interesante es expuesto por Juanita Sundberg (2014) que toma la idea de 'caminar con' (walking with) del movimiento Zapatista como estrategia de transformación y construcción de otras formas de conocimiento y alternativas futuras.

Del entrecruce entre las ideas posestructuralistas y decoloniales, las reflexiones actuales en la EPF se debaten entre la realidad que representan las categorías binarias de hombre/mujer y nociones mucho más complejas del género (Hawkinsy Ojeda, 2011). Sobreeste último punto, intelectuales y activistas en toda la región, han mostrado la importancia de visibilizar las construcciones de género andinas y mesoamericanas. Al respecto, Caterine Walsh (2015) plantea que estas culturas compartían la existencia de una dualidad de género que implicaba una interpenetración de lo masculino y lo femenino, la existencia de entidades que incorporaban ambas características, o combinaciones y continuos que se movían entre ellas. Llevando estas ideas más allá, Walsh cita los planteamientos de Rita Segato y Julieta Paredes, para señalar que una auténtica descolonización del género y del feminismo implica también reconocer que el patriarcado no empezó con la conquista, ni con el sistema colonial-moderno (Curiel, 2009. Citado en Bolados, 2018) y que la opresión de las mujeres también tuvo su versión precolombina.

Por su parte, la influencia del pensamiento decolonial en la EPF implica también repensar y profundizar la idea de interseccionalidad que, siendo importante desde los orígenes de este sub-campo (Rocheleau, et al. 
2004), adquiere un sentido diferente al considerar las formas racializadas de discriminación hacia las mujeres, cuya raíz colonial sigue atravesando estructuras económicas, sociales, culturales y políticas hasta nuestros días. Esto, desde luego, también imprime tensiones al interior de los feminismos latinoamericanos que se anclan en las visiones moderno/occidentales. Como bien sintetiza, Iris Hernández:

“(...) la conquista de Abya Yala impuso un sistema de relación entre hombres y mujeres a la usanza del conquistador, borrando experiencias. Otras vinculadas a comunidades en donde mujeres y hombres ejercían el poder en igualdad de condiciones, en donde mujeres ejercían el poder, en donde se valoraba o no la homosexualidad, en donde existían rasgos pre-patriarcales o patriarcales con distintas intensidades. La diversidad cultural que esto representaba fue borrada, instalándose un sistema único de opresión de la mujer. En este punto es donde emerge la paradoja feminista, pues su legítima lucha opera en esta imposición colonial, omitiendo que a no todas las mujeres se les oprime de la misma forma” (Hernández, 2018, p. 25).

Como veremos a continuación el impacto de las corrientes postestructuralistas y postcoloniales/ decoloniales, se traducirá en aportes y matices específicos en sus distintas líneas de desarrollo.

\section{Impactos y experiencias generizadas}

Una de las líneas de trabajo clásicas y más consolidados de la EPF, viene del legado marxista de la ecología política y se focaliza en las diferencias de género en torno al acceso y control de recursos, incluyendo las relaciones de poder que abarcan desde el nivel global hasta el doméstico(Elmirts, 2018). Aquí, volvemos la mirada hacia la distinción binaria (occidental) entre hombres y mujeres, en tanto categorías que siguen "funcionando" en la realidad actual (Hawkinsy Ojeda, 2011).Así,creemos que sigue teniendo sentido relevar las desigualdades vividas por las mujeres y visibilizar sus experiencias, particularmente considerando los efectos diferenciados provocados por cambios e intervenciones ambientales.

SegúnElmhirst (2018), algunos trabajos recientes en esta dirección han buscado relevar los impactos de la neoliberalización de la naturaleza, enfatizando las consecuencias diferenciadas del despojo y acaparamiento de recursos en el Sur global. Otras indagaciones, han comenzado a mostrar cómo las consecuencias de la crisis climática son experimentadas de manera diferenciada entre los géneros y las maneras (también disímiles) en que hombres y mujeres se adaptan a estos (Ibid.).Estas investigaciones llaman a profundizar los análisis multiescala propios de la EPF, lo que implica dar cuenta de las conexiones globales y,simultáneamente, de las experiencias íntimas en torno a las transformaciones ambientales.

Un área interesante de desarrollo en esta línea dice relación con el análisis de las subjetividades de género en torno a los impactos mencionados, donde se retoma el componente interseccional de las experiencias, así como los elementos corporales y emocionales asociados a las vivencias cotidianas. Aquí, una importante fuente de inspiración proviene de los trabajos de Leila Harris y Farhana Sultana. Al respecto, Harris (2015b) rescata la potencialidad de la EPF para considerar las relaciones cotidianas, incorporadas y emocionales (o las 3 'E's, por everyday, embodied and emotional)con los recursos y las 'naturalezas'. Por su parte Sultana (2011), indaga en el repertorio diferenciado de emociones asociado a la búsqueda de agua, concluyendo que las mujeres al buscar la provisión de un recurso escaso y contaminado, también sufren las distintas consecuencias de adquirirlo y consumirlo.

Nos interesa aventurar los posibles entrecruces entre tales planteamientos y las investigaciones en América Latina, construidas sobre la base del concepto de Sufrimiento Ambiental, de Auyero y Swistun (2008). Este concepto aborda relaciones de dominación enfatizando lo que ocurre en contextos de espera, incertidumbre y confusión sobre los problemas ambientales, donde además no existe acción colectiva. En esta línea, el énfasis inicial en desigualdades de clase/territorio se ha abierto al entrecruce entre dichos ejes y el género (Arriagada, 2020), mostrando cómo las 'experiencias tóxicas' también se viven de forma diferenciada y desigual entre hombres y mujeres. 


\section{Viejas y nuevas formas de agencia}

Así como es importante seguir dando cuenta de los impactos diferenciados de las intervenciones y transformaciones ambientales, también es importante continuar y profundizar en la agenda EPF que describe las múltiples manifestaciones colectivas que se estructuran en el entrecruce género-medioambiente. Así, un renovado foco en las múltiples formas de agencia ha sido desarrollado por una nueva camada de EPF en el Norte, para mover el foco desde las vulnerabilidades hacia la acción, poniendo acento en las formas de adaptación, resistencia e innovación consideradas como fundamentales para enfrentar los desafíos que emanan de la crisis climática (Buechlery Hanson, 2015). Para nosotras, la relevancia de teorizar y documentar en esta línea de trabajo implica considerar incluso aquellas expresiones que no se declaren abiertamente como feministas y/o ambientalistas. Esto reviste especial relevancia en un escenario donde la mayoría de las investigaciones en torno a conflictos ambientales sigue haciendo escasas referencias a las dinámicas de género que los atraviesan.

Considerando el contexto latinoamericano, nos interesa mostrar tres caminos posibles para profundizar el marco interpretativo y describir los repertorios de organización, acción colectiva y militancias ambientales. En primer lugar, son relevantes los ejercicios que se han desplegado en la región para documentar las múltiples manifestaciones que asume el "imaginario ecofeminista" (LaDanta LasCanta, 2017) o los feminismos comunitarios latinoamericanos. Esta ruta muestra continuidad con la tradición de los feminismos comunitarios en América Latina, pero asume nuevas formas a través de la crítica a los modelos extractivistas y su relación con el capitalismo y el patriarcado. Si bienla producción académica y política que se ubica en este espectro se ha multiplicado en los últimos años, nos interesa destacar aquídos publicaciones recientes que lograncondensar un amplio abanico de reflexiones y formas de organización.. Se trata del número 54 de los Cuadernos de Ecología Política y de la publicación denominada "Mujeres en Defensade Territorios", de la Fundación Heinrich Böll (2018). Ambas son, además, de libre acceso y están escritas en castellano. Aunque todas las contribuciones presentes en ambos compilados son interesantes e iluminadoras, quisiéramos destacar los trabajos de Paola Boladosen ambas publicaciones, para hablar de y con las "Mujeres de Zonas de Sacrificio en Resistencia”, de Puchuncaví-Quintero. De los discursos y prácticas de este movimiento surge una fuerte crítica al modelo extractivista, que obliga a las mujeres a desarrollarse en torno al cuidado. Esto relega a las mujeres a la explotación, pues desempeñan un trabajo no-remunerado que subsidia las ganancias de estas compañías, y las expone a enormes daños en su salud y las de sus familiares. Es interesante también como estas mujeres buscan transformarse en agentes, que innovan en las formas de organización y protesta colectiva, a la vez que buscan redefinir su vínculo con la naturaleza y las comunidades, para transformar sus territorios de zonas de sacrificio a zonas de recuperación (Bolados y Sánchez, 2017; Bolados, et al. 2017; Bolados, 2018).

En segundo lugar, el trabajo de muchas exponentes de la EPF y de otras intelectuales y activistas ubicadas en campos cercanos a esta, muestran la relevancia de explorar la multiplicidad de formas de agencia de las mujeres, muchas veces invisibilizadas ante la participación pública en protestas o en negociaciones con autoridades.Aquí, las nociones de vida cotidiana y resistencia - con una larga tradición en los estudios feministas- sedirigen hacia una búsqueda más amplia de formas de participación política. Al respecto, nos parece interesante hacer seguimiento al trabajo de Katy Jenkins (2017)sobre activismo femenino antiminero en América Latina.Siguiendo los planteamientos de Scott y Amoore sobre formas de resistencia cotidianas, Jenkins plantea que entender las actividades desempeñadas diariamente por las mujeres permite comprender cómo se mantiene ese activismo a lo largo del tiempo, en circunstancias a menudo desafiantes y aisladas. Su teorización resalta la importancia de hacer visibles las prácticas locales y domésticas, considerandosu relevancia política y social. De este modo, busca mostrar acciones e interacciones que, a menudo, se interpretan como insignificantes y que se esconden detrás de la espectacularidad de las grandes movilizaciones.

Una tercera línea de interpretación, que resuena en nuestro propio trabajo, surge en torno a la idea de politización de maternidad ${ }^{5}$, que siendo parte del repertorio histórico de movilizaciones en Latinoamérica (Molyneux, 2003),adquiere nuevas expresiones en torno a las luchas ambientales.

Así, por ejemplo, en su trabajo con las mujeres Xapuri en Brasil, Connie Campbell (1996) mostraba la importancia de la maternidad en la identidad de género de las mulheres seringueiras. De forma similar, en 
trabajos anteriores, hemos mostrado cómo muchas dirigentes de base - tanto en ciudades del norte como en localidades rurales de la zona central en Chile - se involucran en acciones ambientales motivadas por sus roles como madres o cuidadoras (Arriagada, 2020; Zambra y Arriagada, 2019).Particularmente, en el caso de las 14 dirigentas de Arica (Norte de Chile), es posible apreciar cómo la intuición y el cuidado operan como mecanismos de alerta y de acción. Esto permite un proceso de politización donde el cuidado se amplía a la comunidad, se interpretala propia situación como causada por factores estructurales y se le otorga un nuevo significado a la experiencia cotidiana. Así, maternidad y activismo se alimentan mutuamente, cuestionando la división entre lo privado y lo público o entre lo social y lo político (Arriagada, 2020).

De este modo, las investigaciones recientes en la región permiten comprender un amplio abanico de formas de activismo y organización de las mujeres que se involucran en cuestiones ambientales. Estas investigaciones aportan conceptos y experiencias que redefinen la relación entre género, ambiente y política, y muestran las continuidades y discontinuidades entre las experiencias cotidianas y los grandes procesos económicos y ecológicos que afectan sus vidas y las de sus comunidades.

\section{La EPF como lugar de praxis política}

En este último apartado, nos interesa mostrar cómo la EPF se nutre de las teorías postestructuralistas y decoloniales para reforzar su carácter de proyecto que - simultáneamente - es intelectual y político. Al respecto, queremosdestacar que el renovado énfasis en la agencia no solo implica continuar teorizando y documentando activismos y luchas, sino también revisar de forma permanente los efectos performativos que dichos insumos generan. Por ejemplo, preguntarse cuánto de lo que presentamos como parte de nuestros hallazgos reproduce o agudiza visiones peyorativas sobre las mujeres subordinadas, o cómo imponemos categorías ajenas y opuestas a las que las mujeres ya tienen sobre sí mismas, o simplemente cómo tomamos prestadas su historias y testimonios para exponerlos sin medir las consecuencias que eso puede traer para sus vidas.

Tomar conciencia de los efectos performativos de lo que se produce en la academia, implica un mandato mayor para quienes nos situamos en el campo de la EPF, pues suponela decisión de involucrarse, para acompañar, caminar con (al decir de Sundberg) o proponer - parafraseando a Escobar - "mundos y conocimientos de otro modo" (Escobar, 2003). Al respecto, adscribimos al llamado de Harris (2015b) para construir, desde la EPF, alternativas contrahegemónicas a la gobernanza ambiental neoliberalizada, y también a aquellas propuestas que - del reencuentro entre ecofeminismo y feminismos comunitarios - reimpulsan la ética del cuidado como horizonte político alternativo (Elmhirst, 2018; Bolados y Sánchez, 2017).

Decir que la EPF es un lugar político-intelectual para proponer la construcción de otros mundos, implica también llevar la idea de la descolonización del saber a la práctica investigativa y a las relaciones con aquellas organizaciones, movimientos y comunidades de mujeres afectadas por cambios e intervenciones ambientales, o que están problematizando/actuando en defensa de sus territorios. Como plantea Elmhirst:

"El pensamiento decolonial va más allá de una provincialización poscolonial de los conocimientos occidentales y alienta a repensar el mundo desde América Latina, desde África, desde los lugares indígenas y desde la academia marginada en el Sur global (Radcliffe 2017) para desafiar afirmaciones universalizantes que subordinan otras formas de conocimiento" (Elmirts, 2018, p. 57)

Así, desde nuestra propuesta, el giro decolonial en la EPF implica movimientos epistemológicos que no solo conectan el Norte y el Sur, sino también distintas corrientes de pensamiento y prácticas políticas entre distintos puntos del Sur, a la vez que abren nuevas posibilidades de creación de conjunta de conocimientos entre la academia y activismo.

Para algunas exponentes de la EPF este movimiento ha implicado el llamado a trabajar colaborativamente (Sundberg, 2014) - como hizo Campbell (1996) con las mujeres Xapuri en Brasil - obien ha generado prácticas de innovación y experimentación metodológica, donde destaca la escritura conjunta (Bolados et al., 2017; Hayman et al. 2015) o la colaboración en redes internacionales de académicas y activistas (Perkins y Figuereido, 2015).Al respecto, también se enfatiza la incorporación de fuentes audiovisuales y prácticas artísticas, para 
generar formas más complejas y colectivas de interpretación de la realidad - como propone Silvia Rivera Cusicanquí (2015)-opara acercar conocimientos especializados a audiencias más amplias (Harris 2015a).

En esta línea de desarrollo nos interesa reforzar el cruce entre el feminismo y los aportes de pensadores y pensadoras de nuestra región, que desde mediados del siglo XX han venido teorizando y experimentando formas de encuentros epistemológicos, teóricos y metodológicos con los movimientos sociales. Al respecto, una fuente de inspiración que tiene eco en nuestro trabajo viene de la mano de los planteamientos de Orlando Fals-Borda, particularmente de su idea de compromiso-acción y su propuesta de investigación-acción (FalsBorda, 2009). Así, nos situamos como investigadoras comprometidas que buscan tomar y problematizar el conocimiento producido en la academia, para abrirlo a un proceso de aprendizaje y acompañamiento de comunidades y organizaciones de mujeres que están reflexionando y actuando a partir de su relación con el ambiente. Este proceso se ha materializado en la "Escuela de dirigentas en temáticas socio-ambientales" ${ }^{\text {, }}$, que ha buscado relevar la problemática ambiental territorios rurales en la zona central de Chile, desde una perspectiva de género y teniendo como eje articulador el lente de la Ecología Política Feminista y el enfoque de la investigación acción participativa ${ }^{7}$ (Zambra y Arriagada, 2019).Al igual que esta iniciativa, otras escuelas de formación inspiradas en la educación popular de Paulo Freire, también ha proliferado en la región ${ }^{8}$, constituyéndose como espacios donde es posible el encuentro, la co-construcción de conocimientos y la imaginación política, en un intento conjunto por superar las brechas entre academia y movimientos sociales, y entre teoría y práctica.

\section{Reflexiones finales}

En las páginas anteriores, hemos fundamentado la necesidad de construcción de una Ecología Política Feminista desde Latinoamérica y hemos esbozado algunos puntos de convergencia y vías de articulación posibles entre sus desarrollos en el Norte y los aportes desde nuestra región. A pesar de la multiplicidad de formas de teorizar y actuar en el entrecruce género-medioambiente, desde una perspectiva situada, queremos defender el lugar de la Ecología Política Feminista como una apuesta intelectual y política. Como aporte intelectual, son innegables sus ventajas conceptuales y analíticas para abordar las relaciones de mutua influencia entre los elementos estructurales y agenciales que permean la relación de los distintos géneros con la naturaleza. Asimismo, su carácter multiescalar permite problematizar las complejas relaciones de poder que se cruzan e interactúan entre las esferas domésticas y las esferas globales. Por su parte, el foco en la interseccionalidad de las desigualdades permite repensar y rearticular la Ecología Política más allá del foco tradicionalmente puestoen la clase, incorporando el género como categoría clave (así como otros ejes de diferenciación tales como raza, etnia, edad, etcétera) para abordar procesos y experiencias diferenciadas en el acceso y tenencia de recursos, cuerpos y materias, bienes comunes o el cuidado. Estas cuestiones, que forman parte del corazón de la EPF, desde sus orígenes, asumen nuevos énfasis, con la influencia transversal del pensamiento posthumanista, y de las ideas postcoloniales y decoloniales. Estos nuevos énfasis permiten un reencuentro con los ecofeminismos latinoamericanos y del Sur global, a la vez que posibilitan la necesaria apertura a las conceptualizaciones, experiencias y aportes investigativos, tanto de la academia como del activismo latinoamericano.

Como lugar de construcción política, por su parte, la EPF permite problematizar los efectos performativos de la construcción de conocimientos, y proponer críticamente alternativas e innovadoras para decolonizar los saberes. Al respecto, nuestra propuesta buscar recuperar los aportes de pensadores clásicos como Fals-Borda o Paulo Freire, además de visibilizar las historias, reflexiones y prácticas del ecofeminismo latinoamericano, para ensayar, replicar o expandir praxis innovadoras en nuestra región. En esta línea, hemos querido mostrar aportes recientes que intentan formas colaborativas de escritura, formación eco-política y co-producción de obras artísticas o visuales, en todo el continente. Sobre la base de estos cimientos, y en diálogo crítico con el planteamiento de la EPF del Norte, esperamos contribuir desde Latinoamérica al cierre de las brechas Norte-Sur, teoríapráctica y academia-activismo. Así, para nosotras, la práctica política de la EPF, está llamada también a plantearse como un espacio de pensamiento y propuesta de formas alternativas de sociedad, y de relación entre humanos y naturaleza. En esta apuesta de futuro, la visión de las mujeres, académicas y activistas de nuestra región, no puede estar ausente. 


\section{Notas}

${ }^{1}$ Las corrientes post-humanistas en Ecología Política pondrán el foco en las relaciones y procesos de mutua constitución de sujetos y naturalezas. Incluyen el estudio de las ecologías políticas del cuerpo y las fuerzas estructurales que lo producen, la producción de conocimiento y creación de significados, relación entre sistemas socio ambientales materializados en dinámicas afectivas y emocionales, por nombra algunos (Elmhirst, 2018; Ojeda, 2011).

2 Fundador y editor de la revista Ecología Política; publicada en Barcelona desde 1991 y referencia obligada para académicos y activistas de América Latina interesados en el abordaje de las desigualdades, conflictos, resistencias y políticas ambientales en el mundo.

${ }^{3}$ Este colectivo nace en 1991 y cuenta con distintos espacios de formación,reunión y difusión de su pensamiento. Ver en http:// conspirando.cl/

${ }^{4}$ Traducción propia.

${ }^{5}$ Es importante distinguir la politización de la maternidad, de lo que se ha llamado la "politización de los cuidados". Si bien la primera utiliza al cuidado como forma de agencia, la segunda implica más bien un cuestionamiento explícito del cuidado como tarea esencialmente femenina, su visibilización en la escena pública y la búsqueda de su reconocimiento (incluso monetario) como trabajo.

\footnotetext{
${ }^{6}$ Se trata de un trabajo conjunto entre el Observatorio de Desigualdades (Universidad Diego Portales), la Fundación para la Superación de la Pobreza de la Región Metropolitana (FUSUPO) y el Centro de Estudios del Conflicto y la Cohesión Social (COES), que para el año 2019 va en su segunda versión.

${ }^{7}$ Entre estas problemáticas destacan la desaparición gradual de actividades agrícolas, debido a la escasez de agua en pozos y norias, o problemas a la salud por contaminación de aire, agua o suelo, por nombrar algunos.

${ }^{8}$ Un ejemplo interesante es el de las Escuelas de la Sustentabilidad Mujer y Minería, en Colombia, creadas por la organización CENSAT Agua Viva - Amigos de la Tierra. Más informaciónen https://www.redlatinoamericanademujeres.org/images/red_mujeres/recursos/publicaciones/cartilla9.pdf
}

\section{Bibliografía}

Alimonda, H. (2006).Una nueva herencia en Comala. Apuntes sobre la ecología política latinoamericana y la tradición marxista. En Gandásegui, M. (ed). Los tormentos de la materia. Aportes para una ecología políticalatinoamericana. (pp. 93-121). Buenos Aires, Argentina: CLACSO.

Alimonda, H. (2011). La colonialidad de la naturaleza. Una aproximación a la ecología política latinoamericana. En Alimonda, H. (Coord.). Naturaleza colonizada. Ecología política y minería en América Latina (pp 2158). Buenos Aires, Argentina: CLACSO.

Arriagada, E. (2020). Las “madres del plomo": women’s environmental activism and suffering in Northern Chile. En Ramm, A. y Gideon, J. (eds.) Motherhood, Social Policies and Women's Activism in Latin America (pp. 145-165). New York, USA: Palgrave Macmillan. DOI: https://doi.org/10.1007/978-3-030-21402-9_7

Auyero, J. y Swistun, D. (2008). Inflamable. Buenos Aires, Argentina: Paidós.

Bolados, P. y Sánchez, A. (2017). Una ecología política feminista en construcción: El caso de las "Mujeres de zonas de sacrificio en resistencia”, Región de Valparaíso, Chile. Psicoperspectivas, 16 (2), 33 - 42. Recuperado en: http://www.redalyc.org/articulo.oa?id=171053168004

Bolados, P. Sánchez, A. Alonso, K. Orellana, C. Castillo, A. Damann, M. (2017) Ecofeminizar el territorio. La ética del cuidado como estrategia frente a la violencia extractivista entre las Mujeres de Zonas de Sacrificio en Resistencia (Zona Central, Chile). Ecología Política (54): 83 - 88. Recuperado en: https:// www.ecologiapolitica.info/?p=10162

Bolados, P. (2018). Acuerpándonos frente al extractivismo minero energético. En Erpel, A. (comp.). Mujeres en defensa de territorios. Reflexiones feministas frente al extractivismo (pp.8-19). Fundacion Heinrich Böll, 
Oficina Regional Cono Sur. Recuperado en: https:/cl.boell.org/sites/default/files/ mujeres_defensa_territorios_web.pdf

Buechler, S. y Hanson A. M. (2015). A Political Ecology of Women, Water and Global Environmental Change. New York, USA: Routledge.

Bustos, B; Prieto, M \& Barton, J. (2015). Ecología Política en Chile. Naturaleza, Propiedad, Conocimiento y Poder. Santiago, Chile: Editorial Universitaria.

Butler, J. (1999). Gender trouble: feminism and the subversion of identity. New York, USA: Routledge.

Campbell, C. (1996) [en colaboración con el grupo de mujeres de Xapuri]. Out on the frontlines but still struggling for voice. En Rocheleau, D., Thomas-Slayter, B. y Wangari, E. (eds).Feminist Political Ecology: global issues and local experiences. New York, USA: Routledge.

Carcaño, É. (2008). Ecofeminismo y ambientalismo feminista. Una reflexión crítica. Argumentos, 21, (56). 183188 UNAM Unidad Xochimilco Distrito Federal, México. Recuperado en: https://www.redalyc.org/pdf/ 595/59505610.pdf

Elmhirst, R. (2018). Ecologías políticas feministas: perspectivas situadas y abordajes emergentes. Ecología Política. Cuadernos de debate internacional (54) 52 - 59. Recuperado en: https://www.ecologiapolitica.info/ ?p=10162

Elmhisrt, R. (2011). Introducing new feminist political ecologies. Geoforum (42) 129-132. DOI: https://doi.org/ 10.1016/j.geoforum.2011.01.006

Escobar, A. (2003). Mundos y conocimientos de otro modo. El programa de investigación de modernidad/ colonialidad latinoamericano. Tabula Rasa (1) 51-86. Recuperado en: http://www.revistatabularasa.org/numero-1/escobar.pdf

(2011). Ecología política de la globalidad y la diferencia. En Alimonda, H. (Ed). Naturaleza colonizada. Ecología política y minería en América Latina (pp. 61-92). Buenos Aires, Argentina: CLACSO.

Fals-Borda, O. (2009). La crisis, el compromiso y la ciencia. En Fals-Borda, O. Una sociología sentipensante para América Latina. Bogotá, Colombia: Siglo del Hombre Editores CLACSO.

Harcourt, W. y Nelson, I. (2015). Practicing feminist political ecologies. Moving beyond the 'Green Economy'. London, UK: Zed Books.

Hawkins, R. y Ojeda, D. [con Asher, K., Baptise, B., Harris, L., Mellott, S. Nightingale, A., Rocheleau, D., Seager and J., Sultana, F.] (2011). A discussion: Gender and environment: critical tradition and new challenges. Environmment and Planning D: Society and Space, 29 (2): 237 - 253. DOI: https://doi.org/10.1068\%2Fd16810

Harris, L. (2015a). Foreword. A quarter century of knowledge and change: pushing feminism, politics, and ecology in new directions with feminist political ecology. En Buechler, S. y Hanson, A.M. A Political Ecology of Women, Water and Global Environmental Change. New York, USA: Routledge.

(2015b). Hegemonic waters and rethinking natures otherwise. En Harcourt, W. y Nelson, I. (2015). Practicing feminist political ecologies. Moving beyond the 'Green Economy'. (pp. 157-181) London, UK: Zed Books.

(2017). Theorizing Gender, Ethnic Difference and Inequality in relation to water access and politics in southeastern Turkey. En Ashcraft, C. \& Mayer, T. The Politics of Freshwater: Access, Conflict and Identity, New York, USA: Routledge. 
Hayman, E. [en colaboración con Mark Wedge/Aan Gooshú y Colleen James/Gooch Tlaá] (2015). Storytelling wáter north of the future Héen Kas'él’ti Xoo (among the ragged lakes): collaborative water research with Casrcross/Tagish First nation, Yukon Territory, Canada. En Buechler, S. y Hanson A. M. A Political Ecology of Women, Water and Global Environmental Change. (pp. 185-205)New York, USA: Routledge.

Hernández, I. (2018). Trascender la diferencia colonial. Otras miradas sobre el extractivismo. En Erpel, A. (Comp.). Mujeres en defensa de territorios. Reflexiones feministas frente al extractivismo (pp.8-19). Fundacion Heinrich Böll, Oficina Regional Cono Sur. Recuperado en: https://cl.boell.org/sites/default/files/ mujeres_defensa_territorios_web.pdf

Jenkins, K. (2017). Women anti-mining activists' narratives of everyday resistance in the Andes: staying put and carrying on in Peru and Ecuador. Gender, Place \& Culture, (24):10, 1441-1459, DOI: https://doi.org/10.1080/ 0966369X.2017.1387102

LaDanta LasCanta. (2017). De la teología al antiextractivismo: ecofeminismos en Abya Yala. Ecología Política. (54): 37 - 43. Recuperado en: https://www.ecologiapolitica.info/?p=10162

Leff, E. (2006). La ecología política en América Latina. Un campo en construcción. En Gandásegui, M. (ed). Los tormentos de la materia. Aportes para una ecología política latinoamericana (pp.21 - 39) Buenos Aires, Argentina: CLACSO

Leff, E. (2012). Ecofeminismo: el género en el ambiente. Polis, Revista Latinoamericana(9), 1-9. Recuperado en https://journals.openedition.org/polis/7248

Martínez-Alier, J. (2006). Los conflictos ecológico-distributivos y los indicadores de sustentabilidad. Polis. Revista Latinoamericana (13): 1-15. Recuperado en: https://journals.openedition.org/polis/5359

Molyneux, M. (2003). Movimientos de mujeres en América Latina: estudio teoìrico comparado. Valencia, España: Universitat de Valencia.

O’Connor, J. (2000). ¿Es posible el capitalismo sostenible? Papeles de población (6) 24, 9 - 35. Recuperado en: http://www.redalyc.org/pdf/112/11202402.pdf

Palacio, G. (2006). Breve guía de introducción a la Ecología Política (Ecopol): Orígenes, inspiradores, aportes y temas de actualidad. Gestión y Medio Ambiente (9) 3, 7 - 20. Recuperado en: https://revistas.unal.edu.co/ index.php/gestion/article/view/49672

Pérez, L. (2017). Epistemología feministas y conocimientos desde el sur global. Ecología Política (54) 12-15. Recuperado en: https://www.ecologiapolitica.info/?p=10133

Perkins, P. y Figuereido, P. (2015). En Buechler, S. y Hanson A. M. A Political Ecology of Women, Water and Global Environmental Change. (pp. 118-140)New York, USA: Routledge.

Puleo, A. (2002). Feminismo y Ecologismo. El Ecologista (31). Recuperado en: https://www.ucm.es/data/cont/ docs/3-2016-12-01-feminismo_y_ecologia.pdf

Rivera Cusicanqui. S. (2015). Sociología de la imagen. Miradas ch’ixi desde la historia andina.Buenos Aires, Argentina: Ed. Tinta Limón.

Rocheleau, D; Thomas-Slayter, B y Wangari, E. (2004). Género y medio ambiente: una perspectiva de la ecología política feminista. En Vásquez, V. y Velásquez, M. (comp.). Miradas al futuro: hacia la construcción de sociedades sustentables con equidad de género (pp. 343-372). Ciudad de México, México: Centro Internacional de Investigaciones para el Desarrollo. 
Rocheleau, D; Thomas-Slayter, B y Wangari, E. (2004). (Eds.) (1996). Feminist Political Ecology: global issues and local experiences. New York, USA: Routledge.

Sultana, F. (2011). Suffering for water, suffering from water: emotional geographies of resource, access, control and conflict. Geoforum (42). 163 - 172. DOI: https://doi.org/10.1016/j.geoforum.2010.12.002

Sundberg, J. (2017). Feminist Political Ecology. En Richardson, D; Castree, N; Goodchild, M.F; Kobayashi, A; Liu, W \& Marston, R. (ed.), International Encyclopedia of Geography:People, the Earth, Environment and Technology. Chichester, UK: John \& Sons.

Svampa, M. (2015). Feminismos del Sur y ecofeminismo. Nueva Sociedad(256). 127-131. Recuperado en: https:/ /nuso.org/articulo/feminismos-del-sur-y-ecofeminismo/

Walsh, C (2015). Life, nature and gender otherwise: feminist reflections and provocations from the Andes. Harcourt, W. y Nelson, I. Practicing feminist political ecologies. Moving beyond the 'Green Economy’ (pp. 101-128). London, UK: Zed Books.

Zambra, A. y Arriagada, E. (2019). Género y conflictos socioambientales: una experiencia de investigación-acción participativa con mujeres dirigentes. Revista Sociología, 34 (1), 147-165. DOI: 10.5354/0719529X.2019.54270 